\title{
Well-being, context, and everyday activities in space and time
}

\author{
Tim Schwanen \\ Transport Studies Unit \\ School of Geography and the Environment \\ University of Oxford \\ South Parks Road, Oxford \\ OX1 3QY \\ United Kingdom \\ E-mail: tim.schwanen@ouce.ox.ac.uk
}

\author{
Donggen Wang \\ (Corresponding author) \\ Department of Geography \\ Hong Kong Baptist University \\ Kowloon Tong, Kowloon \\ Hong Kong \\ E-mail: dgwang@hkbu.edu.hk
}

Published as:

Schwanen, T., Wang, D. (2014) Well-being, context and everyday activities in space and time. Annals of the Association of American Geographers 104(4), 833-851. 


\begin{abstract}
Against the background of increased interest in subjectively experienced well-being in economics, psychology and the social sciences, this paper analyses how such well-being is associated with geographical context, social contacts, and life circumstances. The empirical analysis of data collected in Hong Kong is used to elaborate and support two main claims. The first is that geography matters to not only overall well-being, but also momentary well-being and that researchers should be careful to specify the influence of geographical context correctly. We therefore employ an approach that is informed by various strands of time-geographical thought, and find that life satisfaction is associated more strongly with geographical context than is momentary well-being. Secondly, we confirm positive relations between social contacts and experienced well-being but extend earlier research by showing that these relations stretch across multiple time scales and depend to some extent on the duration of an activity episode and with whom the activity episode is undertaken. This means that the use of simple indicators of social capital is inadequate for making the complex linkages between well-being and people's social contacts understandable in empirical research.
\end{abstract}

Keywords: accessibility, Hong Kong, social contacts, time-geography, well-being 
In recent years well-being has attracted increasing attention across multiple disciplines, including economics, psychology and sociology (Ryan and Deci 2001; Helliwell and Putnam 2004; Kahneman and Krueger 2006; Diener 2009; Layard 2010). This increased attention reflects increased dissatisfaction with the discord between standard measures of socioeconomic performance and popular perceptions thereof (Stiglitz, Sen and Fitoussi 2009) and advances in neo-liberal styles of government (Binkley 2011). Equally important has been the rise of the "positive psychology" movement and a new scientific discourse according to which happiness is taken to be a transparent, knowable object that can be enhanced through everyday practices and techniques (ibid.).

Geographers have also begun to pay more attention to happiness and well-being. Considerable work has been undertaken by health geographers, for whom well-being provides a useful concept to move beyond biomedical understandings of health (Fleuret and Atkinson 2007; Atkinson, Fuller and Painter 2012). Regional scientists and spatialanalytically inclined researchers are examining spatial variations in well-being to evaluate if and how well-being depends on density and urbanization levels (Berry and Okulicz-Kozaryn 2011; Brereton et al. 2011; Morrison 2011; Ballas and Tranmer 2012; Arifwidodo 2012), access to green space (Van den Bergh et al. 2010), such environmental factors as air quality (MacKerron and Mourato 2009; Ferreira et al. 2013), and social inequalities (Ballas and Dorling 2012) around people's residential location. Nonetheless, and despite economists arguing that "[d]ifferences in well-being across [US] states are ... similar in size to the individual cross-sectional effect on life satisfaction of marital separation or unemployment" (Oswald and $\mathrm{Wu} 2010,578$ ), geographers' engagements with well-being and happiness lag behind the interest in economics, psychology, and sociology. 
Drawing on various strands of time-geography (Hägerstrand 1985), the present study fills two gaps in recent spatial-analytical research of how geographical factors are related to wellbeing. It moves beyond the measurement of subjectively experienced well-being through the indicator of overall life satisfaction to also analyze well-being as produced and rooted in everyday activities, and it examines geographical context by focusing not only on individuals' residential location but also on the place where they are at a given moment in time. In so doing, the article begins to address the uncertain geographical context problem $(\mathrm{UGCoP})$ - spatial and temporal uncertainty about what the areas are that shape behavior and experience (Kwan, 2012) - in the well-being context, and makes optimal use of the opportunities to examine situational variations in well-being that are offered by the data collection technique of the Day Reconstruction Method (DRM) (Kahneman et al. 2004). The DRM was introduced by economists and psychologists to characterize the well-being experience of individuals' daily time use. It does this effectively but also generates more data on and insight into the links between activity participation and well-being than hitherto recognized. Time-geography offers a framework to analyze how the interrelations among multiple dimensions of activity participation affect well-being and thus allows more of the DRM's potential to be realized.

We also seek to extend understandings of how social contacts shape well-being. Numerous studies have found positive correlations of social contacts and social capital with well-being (Helliwell and Putnam 2004; Lyobumirski, King and Diener 2005) but most rely on data about how satisfied people are with life in general and cannot address questions about the specific situations in which social contacts affect well-being. Relying on time-geography and the DRM enables us to foreground the situational dimensions of how social contacts 
influence well-being, and to examine if and how longer-term and momentary well-being are affected differentially by spending time with social ties.

Accordingly, in this article we analyze how variations in subjectively experienced well-being are associated with everyday activity participation, geographical context, social contacts, and life circumstances. Data from 770 adults living in Hong Kong collected via activity and time use diaries are used in a structural equations modeling (SEM) analysis. The remainder of this paper starts with a discussion of well-being as a concept and a brief overview of factors known to influence well-being, which is followed by a discussion of the data, variables and methods and then the empirical results.

\section{Study background}

Well-being

Understandings of well-being abound in the academic literature (Nordbakke and Schwanen 2013). Suffice to say that two key debates regarding well-being revolve around the questions whether objective or subjective perspectives and whether hedonic or eudaimonic understandings should be employed in empirical research. While the subjective perspective holds that individuals' perceptions and experiences are the basis for evaluations of how good life is, the objective perspective implies that well-being can be established from expert evaluations of people's life circumstances. In geography it is exemplified by the influential 'territorial social indicators' approaches in the 1970s (Smith 1973) and more recent work on socio-spatial inequalities in well-being (Pacione 2003; Ballas and Dorling 2012). Ballas 
(2013) usefully reviews the impressive number of geographical studies of objective measures of well-being, making a convincing case for further empirical research into how social justice and inequality affect well-being (see also Wilkinson and Pickett, 2009).

According to a hedonic perspective, well-being should be defined in terms of pleasure experienced and displeasure avoided. Yet, this view is too narrowly focused on the maximization of personal enjoyment for eudaimonic scholars who argue that well-being needs to be considered in terms of flourishing, realizing one's true potential, leading a meaningful life and acting in accordance with one's goals (Ryff 1989; Waterman 1993). Objective and eudaimonic perspectives are widespread, but the combination of subjective and hedonic understandings has attracted most attention outside geography in recent years. Its protagonists consider well-being to be multi-dimensional, encompassing cognitive and affective, and short and long-term aspects. ${ }^{1}$ It is customary to distinguish life satisfaction as a more cognitive evaluation of how good one's life is over a longer period of time from more affective evaluations focusing on a (much) shorter time-span (Diener 2009). The latter are variously called mood and affect. The term happiness is used in multiple ways to denote short-term affect, affective evaluation with reference to longer time scales (as a complement to cognitively oriented life satisfaction), and subjective well-being more generally. We use it in this last manner here.

Subjective well-being is measured in multiple ways (Kahneman and Krueger 2006). In addition to evaluations of life satisfaction and happiness based on large-scale, (nationally) representative surveys, the Day Reconstruction Method (DRM) has recently attracted considerable attention. With the DRM participants are asked to reconstruct the preceding day; identify separate activity episodes therein; describe these in terms of content, duration, 
starting time, company, etc.; and rate each in terms of how much they felt happy, nervous, sad, content, frustrated, tired, etc. (Kahneman et al. 2004; White and Dolan 2009). For Kahneman et al. (2006) the DRM provides more reliable measurements of well-being than survey questions about life satisfaction or happiness because the latter induce focusing illusion: as responses to such questions are only constructed when asked, they are sensitive to the effects of earlier questions on respondents' thoughts and feelings. Other academics contend that survey questions about life satisfaction are reliable and useful (Helliwell 2006). Besides, owing to their straightforward character and ease of interpretation (for respondents), such questions are used in many national and international surveys, meaning that much data is available.

Well-being, context and life circumstances

Not surprisingly, then, most empirical evidence about the determinants of well-being focuses on life satisfaction and measures of overall happiness. This is significant because such factors as people's life circumstances tend to impact satisfaction more strongly than affect (Kahneman et al. 2004). Abundant evidence from across the world indicates that indicators of life circumstances, such as age, marital status, income and education, are correlated with life satisfaction (Blanchflower and Oswald 2008; Dolan, Peasgood and White 2008). Most scholarly attention has been devoted to the relation of income with well-being. Reviewing key studies, Clark, Frijters and Shields (2008) suggest that positive effects of income on wellbeing can be expected in individual-level cross-sectional research but that social comparisons and adaptation over time through habituation to a considerable degree explain the 'Easterlin paradox' of substantial income growth without a corresponding increase in happiness at the aggregate level across the Global North (Easterlin 1995). 
Geographical context. Scholarship on spatial variations in well-being is nascent but rapidly expanding. One emerging insight is that spatial differences in subjective well-being are multiscalar: they have been observed at the international level (Stanca 2010; Elgar et al. 2011), the national and interurban scale (Oswald and Wu 2010; Morrison 2011), the intra-urban level (Arifwidodo 2012), and the neighborhood scale (Cutrona et al. 2005; Van den Bergh et al. 2010).

It also appears that both physical and social dimensions of geographical space are related to well-being. Regarding the former, such indicators as density (Arifwidodo 2012), degree of urbanization (Morrison 2011), city size (Ferreira et al. 2013), accessibility to transport infrastructure (Morrison 2011; Brereton et al. 2011) and to services and facilities (Morrison 2011; Arifwidodo 2012) have been linked to measures of overall well-being. Results differ across studies but a recurrent finding is that life satisfaction and happiness are lower in denser, more urbanized settings (Brereton, Clinch and Ferreira 2008; Berry and Okulicz-Kozaryn 2009; Morrison 2011). However, and ceteris paribus, well-being has also been shown to be greater among individuals in/near the city-centers of London and Bandung, Indonesia (MacKerron and Mourato 2009; Arifwidodo 2012), while density had no statistically significant relation with well-being in several studies (Arifwidodo 2012; Ballas and Tranmer 2012; Ferreira et al. 2013). The effects of accessibility to shops, education, healthcare and/or transport facilities on subjectively experienced well-being are also mixed but often positive (Brereton, Clinch and Ferreira 2008; Brereton et al. 2011; Morrison, 2011; Arifwidodo, 2012). The findings appear least equivocal for access to green space, which usually has a positive impact on well-being and mental health (Guite et al. 2006; Van den Bergh et al. 2010; Morrison 2011), especially when woodlands and parks are visited at least once per week 
(Mitchell 2013). The divergence across studies in results for density, urbanization degree, and accessibility may reflect differences in study design - i.e., differences in sample composition, variable definitions and inclusion of control variables - and contextual variations in the mechanisms through which land use and accessibility affect well-being.

Work on the social dimensions of space tends to address the question whether area-level deprivation or prosperity affects subjective experienced well-being adversely. Using the British Household Panel Study, Ballas and Tranmer (2012) observed few geographical differences in the happiness and life satisfaction of individuals in UK cities with at least 120,000 inhabitants. They nonetheless detected that the negative effect of being unemployed is weaker as the unemployment rate of the metropolitan district of residence increases. These findings replicate those by Clark and Oswald (1994) who used the same data but considered regions defined at a higher level of spatial aggregation. These studies signal how the effects of individuals' life circumstances can be relational and depend on the wider distribution of socioeconomic advantage in a place (Ballas 2013). Additionally, Cutrona and colleagues (2005) and Guite cum suis (2006) found clear effects of area deprivation - as manifested in poverty levels, fear of crime, poor access to health care and recreational activities, lowquality housing, and so forth - on well-being, but these studies focus on indicators of mental health rather than life satisfaction. Nonetheless, White et al. (2013) identified only weak effects of area deprivation on life satisfaction in a recent study using small-area statistical data in the UK. After controlling for individual life circumstances, the authors found no significant effects of living in areas with higher income, employment or crime levels

In sum, although evidence is mounting that spatial differences in long-term, overall wellbeing are multi-scalar and both the physical and social dimensions of geographical space may 
explain such differences, there is not much research on how geographical contexts impact on momentary well-being. The existing literature on geographies of well-being thus needs to be extended by examining spatial variations in subjectively experienced well-being in individuals' daily life. An additional concern that needs addressing is the uncertain geographic context problem (UGCoP) (Kwan 2012). The research discussed above either relies on measures of the geographical context with the residential location as reference location, or relies on geographical indicators that exceed the scale of many people's everyday lives. In both cases the actual areas exerting contextual influences on people's experienced well-being may not be represented completely accurate.

Social context. The effects of social contacts on well-being have been studied extensively in a range of academic disciplines. Positive correlations of happiness and life satisfaction with the number of friends, extent of social support, and quality of interpersonal relationships are "one of the most robust findings in the literature on well-being" (Lyubomirsky, King and Diener $2005,823)$. Studies of eudaimonic well-being have also argued that meaningful interactions with others are part of or enhance people's well-being (Ryff 1989), and there is ample evidence in gerontology that informal social participation, such as visiting friends, consistently enhances well-being in later life (Ritchy, Ritchey and Dietz 2001; Oerlemans, Bakker and Veenhoven 2011).

The effects of social contacts have been measured in many different ways. These include the use of indicators of the size and structure of people's social networks and the availability of social support (Currie and Delbosc 2010), of participation in (different types of) social activities (Ritchy, Ritchey and Dietz 2001), and of social capital - typically understood as the network of social ties and as norms of reciprocity and trust (Helliwell and Putnam 2004; 
Elgar et al. 2011; Morrison 2011). Studies have shown social capital at multiple geographical scales to be associated positively with well-being. Helliwell and Putnam (2004) found statistically significant effects of social capital on both the individual and the national level, but more recent multilevel analysis using data on fifty countries suggests that the effects of social capital need to be located at the individual rather than the country level (Elgar et al. 2011). There are also sub-national geographical dimensions to social capital's effects: part of the inter-urban differences in Morrison's (2011) analysis of life satisfaction and happiness could be explained by variations in trust, sense of community, safety and other dimensions of social capital between the cities considered.

Nonetheless, the relations established in studies using indicators of overall life satisfaction and happiness fail to make clear how interactions with other people as part of everyday life and how people's time use affect well-being. Studies using the DRM potentially provide more detailed insight into such effects but these have so far directed rather limited attention to social contacts. In Kahneman et al. (2004) mean affect ratings varied according to with whom - friends, relatives, partner, children, clients, co-workers, boss and alone - activities have been undertaken but no further analysis is presented. Instead, DRM studies tend to concentrate on the type of activities undertaken with research indicating that socializing and intimate relations score high on positive affect and low on negative affect (Kahneman et al. 2004) and are perceived as very rewarding (White and Dolan, 2009). Childcare is also considered very rewarding but scores considerably worse in terms of pleasure experienced and displeasure avoided. Among retired seniors in the Netherlands social activities tend to increase momentary happiness but primarily for extrovert persons (Oerlemans, Bakker and Veenhoven 2011). Using experimental methods, Walker $(2010,9)$ concluded that "doing it 
together is better than doing it alone" because it produces 'flow' - a state of immersion producing experience of success and competence - which is more enjoyable.

A potential concern with the above studies is that activities are severed from the situation the time of day, the place where they were undertaken, their duration, the position in the daily sequence, the effort needed to travel to the place, and so on - of which they are part.

Situational variations may nonetheless be important, among others because short-term affect exhibits clear diurnal cycles (Stone et al. 2006), which may shape and be shaped by the type of activity, persons involved, place, and activity duration.

\section{A time-geography of well-being}

Drawing on various strands of time-geography (Hägerstrand 1985) can make three contributions to the analysis of subjectively experienced well-being: it allows the UGCoP to be reduced, situational variations in well-being to be examined, and also helps to unravel some of the interactions between short-term and longer-term well-being. Time-geography holds that everyday life can be imagined as a continuous path through space and time, whereby the paths of individuals intersect with those of others, organisms, material objects, and so forth. At the day level an individual's space-time path is a sequence of activities at stationary locations and movements (trips) between locations. The shape of the path is considered the outcome of the interactions between projects - clusters of acts, individuals and items necessary for the completion of an intention-inspired or goal-oriented behavior - and space-time constraints that bind people to particular places at specific times. 
Time-geography's concepts have found much resonance among transport researchers arguing that travel behavior can only be influenced effectively by policy levers if everyday activity patterns and time use is understood (Timmermans, Arentze, and Joh 2002). These researchers have therefore examined daily sequences of activity and travel episodes, as well as individual activity episodes. They commonly describe an activity episode - a series of acts that are continuous in time and undertaken at a single location in space - via a number of interdependent dimensions, of which the type of activity, starting time, duration, spatial location, and the person involved are the most widely analyzed. Causal linkages between these dimensions have also been explored. The duration of an episode, for instance, depends on its purpose, the time of day and the persons involved. Kitamura and colleagues (1981, 1998) show that activities last shorter and are undertaken closer to home if they start later during the day, and Schwanen (2004) that activity episodes last longer when undertaken with someone else instead of alone.

Using insights like these can help well-being researchers to understand in which situations i.e., as part of which activities, where, when and for how long - social contacts affect individuals' short-term well-being and in what ways. Information on all human beings with whom people interact in their daily practices is unlikely to be available but time-geographical analysis allows for precise insights into the question if and how spending time with specific individuals or classes of social ties - e.g., relatives and friends - affects well-being. Adopting a time-geographical lens can also reduce the UGCoP. By using an individual's activity space - the area encompassing all space-time paths a person followed or could have carved out - rather than geographical indicators based on her residential location, analysts can evaluate the influence of the geographical context more precisely (Kwan 2012). Additionally, Hägerstrand (1985) emphasized the importance of local connections and touch: the 
continuous bundling (and unbundling) of an individual's path with (from) the paths of other human beings and material objects is critical to understanding how activities unfold and are experienced. In short, analysts seeking to specify the effects of geographical context on momentary well-being correctly should follow individuals' paths through space and time continuously and link particular sections of space-time paths, such as activity episodes as identified using the DRM, to indicators describing the site where they are rather than to measures that are based on where they live.

Time-geography also helps in understanding how longer-term processes, including evaluations of life satisfaction, are shaping and shaped by everyday activities. Pred (1983) outlined a life path-daily path dialectic: through longer-term projects (paid employment, family, friendships, etc.), people interact with others, ideas, information and objects as part of their daily activities and undergo experiences that help them to define and redefine themselves, to form intentions, and to develop new longer-term projects. Thus, positive (negative) experiences at the level of activity episodes are likely to correlate with positive (negative) evaluations of life satisfaction that pertain to longer time scales. This may reflect both an accumulation of positive (negative) short-term experiences strengthening a disposition of contentment and happiness (discontent and unhappiness), and that proclivity predisposing a person towards experiencing activity episodes in particular times and places as pleasant and meaningful (unpleasant and meaningless). With cross-sectional research it is impossible to disentangle whether the accumulative effect from short to long term or the dispositional impact from long to short term is stronger. Nonetheless, Lyubomirski, Sheldon and Schkade's (2005) meta-analysis by and large corroborated the idea that long-term happiness precedes success and positive affect in daily activities, which suggests that the dispositional impact should not be underestimated. 
Toward the empirical analysis

We expect momentary well-being at the activity-episode level to be a function of activity type, time of day, whether and which other persons are involved, the episode's duration, and the place where it is undertaken. Activity place is used here as shorthand for the physical and social dimensions of the location where the activity episode occurs. Included among the social dimensions are the area's level of deprivation, which can be expected to lower episodelevel well-being. The physical dimension refers to the density and diversity of human activity at the site where the activity episode is undertaken but it is not a priori clear how these would shape well-being. Greater diversity and density might mean that places offer more opportunities for satisfaction of an individual's needs for social interaction, mental stimulation and confirmation of status and taste (Kennedy and Aldolphs 2011), thereby increasing well-being. Yet, they may also produce an overload of sensory experience, fatigue and stress, as well as (fear for) greater contact with unwanted others (Lederbogen et al. 2011) thereby reducing well-being. The balance of positive and negative impacts may vary between geographical settings, individuals and activity episodes.

While the causal relationships between the various activity episode dimensions are complex, a plausible causal structure includes effects from activity type, the time of day and companionship - whether an activity is undertaken alone or with others, and if the latter, with whom - to the place and duration of the episode. Drawing on past human activity studies we also anticipate all activity episode dimensions to depend on life circumstances and accessibility. The latter measures the ease with which people can reach destinations where everyday activities can be undertaken from their home location and is often used as a 
summary indicator of the opportunity structure urban areas or regions offer to individuals or from particular spaces (Geurs and Van Wee 2004). Additionally, life circumstances and accessibility, as well as characteristics of individuals' social networks, may be related to overall well-being (i.e., life satisfaction), which is likely to be greater when episode-level well-being is greater. It is, however, also conceivable that direct associations between accessibility and life satisfaction disappear when the relationships between place and episode-level well-being are taken into account.

[Figure 1 here]

Figure 1 depicts the expected relations among well-being, activity participation, geographical and social context and life circumstances. Several key hypotheses can be fleshed out:

a) Geographical context may shape well-being in two ways, via the physical and social dimensions of the places where activities are undertaken, and via the spatial structure of opportunities for activity participation that individuals' residential location offers (accessibility). One set of relations may be stronger than the other. While social deprivation of the place where activities are undertaken is likely to reduce well-being, the effects of the physical dimensions of places (density and diversity) and of accessibility are not clear a priori. They can be positive or negative.

b) The extent of social contact with others is correlated positively with both short-term and long-term well-being. The effect on short-term well-being differs according to the sort of social tie people spend time with and interacts with how long the shared activity lasts and where it takes place.

c) Long-term and momentary well-being derived from activity participation in specific times and places are associated with each other, due to the accumulation of short-term 
experiences and/or the dispositional impact emerging from long-term contentment and happiness.

\section{Data and methods}

\section{Data and sample}

In order to correctly specify the effects of geographical contexts on momentary well-being, we adopt the activity and time use diary approach to trace individuals' one-day paths through space and time continuously and follow the DRM approach to identify separate activity episodes and assess individuals' affect experience for each activity episode. Participants were asked to identify each activity episode (at a stationary location) and each travel episode over a one-day period starting at 3:00 AM at a pre-determined date. For activity episodes they had to record the starting and ending time, the type of activity undertaken (18 categories), the location, persons involved (family/relatives, friends, online friends, acquaintances, none), and questions about momentary well-being (see below).

The diary was included in an online survey held in July-November 2010 in the Hong Kong Special Administrative Region (HK-SAR). ${ }^{2}$ Randomly selected 1,500 households were recruited in which one adult was willing to participate in the study. They were sent an invitation e-mail with a hyperlink to the online survey. A cash coupon of HKD 50 was offered for each completed questionnaire. In the end 770 individuals (51.3 percent) filled out the online survey completely; we use their one-day diaries for the empirical analysis. The 
sample resembles the Hong Kong population in terms of employment status, housing type, and car ownership (Table 1), although the young and unmarried, women, the higher educated and those on a higher income are over-represented in the sample. These differences imply that caution should be exercised with generalizing the conclusions of the study to the Hong Kong population as a whole (which is not our aim anyway). Representativeness is also less critical when the emphasis is on the relationships between variables (as it is here). In this regard it is important to note that the distribution over the various categories is reasonably balanced for most life circumstances in Table 1.

[Table 1 here]

Measuring well-being

Six variables are used to measure well-being, four of which pertain to momentary well-being at the activity episode level. We follow Ettema and colleagues (2010) in drawing on the core affect approach developed by Russell $(1980,2003)$. For Russell core affects constitute the basic affective qualities of any emotional experience; they are present in all emotional states and can be accessed cognitively rather easily. They vary along two dimensions called valence and activation. Valence is a purely hedonic dimension and ranges from unpleasant to pleasant; activation ranges from quietness to arousal. As Figure 2 shows, well-known emotions are combinations of different positions on these dimensions in an orthogonal design. Following Russell, two single items with seven categories (from very unpleasant to very pleasant, and from not active at all to very active) were included in the time-space diary to capture core affects for each activity episode. 
[Figure 2 here]

Two further items pertaining to activity episodes were included in the time-space diary. One is also hedonic and asked directly how the respondent thought how the episode had affected his/her mood; the response categories were negative, no effect and positive. The final activity-episode item is eudaimonic, pertaining to the extent to which the episode helped the respondent to realize his/her personal goals. It asked whether the episode had realized the respondent's goals to a lesser degree than expected, as he/she had imagined, or to a greater extent than anticipated. To measure well-being for the day as a whole, we include the question "Compared to what the day usually is, how typical was this recorded day?" with five response categories ranging from much worse to much better. Finally, "Taken all things together, how satisfied are you with your life as a whole?" with five response categories from very dissatisfied to very satisfied was included to obtain an indicator of overall life satisfaction.

Variables used in the analysis

We also selected a series of indicators to measure the various dimensions of activity episodes depicted in Figure 1. Five activity types are distinguished: sleeping at home; maintenance at home (personal care, housework, care-giving); shopping, errands and personal affairs outside the home; leisure at home; and leisure and social visits outside the home. This last category includes visits to parks, sports grounds, places of entertainment, food premises, and the home of friends or relatives. Paid employment and education are excluded from the analysis 
because no information on companionship was recorded for this activity type in the timespace diary. Three categories of companionship are considered: family/relative and/or partner; friends, online friends and/or acquaintances; and none. Note that the label "no companion" does not mean that no social contact has occurred at all. If, for instance, a person visits a sport's club or a shop on her own, she may still encounter other people in their capacity of salesperson, other users of the facility, and so on. She would not, however, consider them part of her network of (strong) social ties and the interactions would often have a more fleeting character.

Of the other episode dimensions considered, duration is a continuous variable measured in hours, and time of day a categorical variable. Activity place is operationalized through a range of variables pertaining to both the physical and social dimensions of the site where activity episodes were undertaken. The physical dimensions of diversity and density are measured through population density (in 10,000 residents $/ \mathrm{km}^{2}$ ) and land use mixing. The latter distinguishes locations with mixed land uses from residentially and tourism oriented locations. The social dimensions - deprivation - were operationalized using five variables: the median monthly income (in 10,000 $\mathrm{HK} \$$ ) and the shares of single-parent households, elderly $(\geq 65)$ residents, public housing and residents with tertiary education. Data on all these variables are from the 2011 Hong Kong population census, which are specified at the level of the District Council Constituency Area (DCCAs) comparable in size to the US census tract. In 2011 the HK-SAR consisted of 412 DCCAs.

The potential effects of accessibility are captured with a gravity-based measure, which is defined as $H_{i}=\Sigma_{j} \frac{P_{j}}{D_{i j}}$, and where $i$ and $j$ are large planning units or neighborhoods of which there are 109 in the HK-SAR; $P_{j}$ is the population size of $j$; and $D_{i j}$ the straight-line distance 
between $i$ and $j$. This indicator summarizes spatial variations in the relative ease with which opportunities for activity participation in different neighborhoods - proxied by their population size - can be accessed from residential locations across the HK-SAR. The survey did not include extensive questions about the size, composition, and structure of people's ego-centered social networks. Nonetheless, questions were asked about how many relatives, friends, online friends and acquaintances respondents had contact with face-to-face or via phone, text, internet, etc. in the previous week. The total number of such contacts is used here as a proxy of the size and intensity of interaction with one's social network. Finally, seven indicators of life circumstances are considered: gender (male versus female); age (<30y; 30$49 \mathrm{y} ; \geq 50 \mathrm{y}$ ); household size (treated as a continuous variable); monthly household income (11 categories treated as a continuous variable); educational status (5 categories treated as a continuous variable); employment status (employed/self-employed versus otherwise); and housing status (public housing/subsidized housing versus otherwise).

\section{Structural equation modeling}

Structural equations modeling (SEM) is used for the analysis because this technique allows for more complex patterns of statistical relationships between variables than does conventional regression analysis (Bollen 1989). In SEM a distinction is made between the measurement and structural model. The former captures the relations between several observed indicator variables and the underlying latent construct, the latter the relations among the latent constructs. In our analysis there are potentially two latent constructs built out of multiple observed variables: activity place and episode-level well-being. In all other cases the observed variable equals the structural construct. In the structural model the relationship 
between two variables can be direct or indirect. A direct effect means that variable A has an effect on B without the involvement of other variable; in the case of an indirect effect A affects B via one or more other variables. Direct and indirect effects can be summed, and the total effect of A on B is the sum of the direct and all indirect effects from one construct to another. There are various methods for estimating coefficients in SEM (Browne 1984); we use the Means- and Variances-adjusted Weighted Least Squares (WLSMV) method as this is recommended for analyses in which multiple non-normally distributed continuous and categorical variables are included (Finney and DiStefano 2006).

\section{Descriptive analysis}

As an introduction to the modeling results we briefly discuss some bivariate statistical analyses. With regard to activity type, Table 2 shows that leisure and social visits outside the home consistently have the highest scores on all well-being indicators. They provide the most pleasure and excitement, improve mood the most, and realize goals to the greatest extent. They also made people think about the day as a whole most positively, which may suggest that their beneficial effects spill over into subsequent activities. Sleeping stands out because of a combination of comparatively high levels of pleasure and de-activation. Overall, however, the average scores on the core affects are relatively similar across activity types: the vast majority of episodes fall in the lower right quarter of Figure 2, producing experiences of contentment and serenity. If we follow the claim from cultural psychology (Tsai, Knutson and Fung 2006) that calmness is more valorized in Chinese culture than in Western culture (which is biased towards the upper right quarter in Figure 2), then our findings seem to suggest that our study participants have internalized those culturally inflected notions of what 
counts as a good life and that the non-employment activities we have considered on balance make them (reasonably) happy.

Table 2 also shows that participation in out-of-home activities is beneficial in terms of wellbeing at the day level but that there are no statistically significant differences between activity participation and life satisfaction.

\section{[Table 2 here]}

The relationship between geographical context and well-being is weak. Regarding the site where activity episodes are undertaken, differences in well-being are also small. Activities at sites with land use diversity are experienced as significantly more exciting and marginally (but not significantly at $p<0.05$ ) more pleasurable than those in places that primarily have a residential function. Participation in activity episodes at mixed-use locations is also associated with higher levels of life satisfaction. For population density all correlation coefficients are very close to zero and hence not statistically significant $(p<0.05)$. For the social characteristics of activity sites there are clearer associations with well-being. If an activity was conducted in an area with a higher median income or with a greater proportion of highly educated residents, the study participants felt more excited and elated. This is because the correlation coefficients of median income and share of highly educated residents with both valence and activation are positive, although only statistically significant $(p<0.05)$ for the valence dimension. The opposite can be observed for areas with many single-parent households or public housing: activities undertaken there were to a greater extent rated as depressing and dull. In all cases, however, the relationships between the site characteristics and valence and activation are weak as the magnitude of the correlation coefficients indicates. 
Additionally, the age composition of residents in the places where activities were undertaken does not seem to bear on momentary well-being, and none of the social indicators of place is associated at $p<0.05$ with participants' mood or the extent to which they felt their goals had been realized.

At the same time, for all site characteristics except density the correlation coefficients with life satisfaction are statistically significant $(p<0.05)$ and have the expected signs, and the associations are stronger for life satisfaction than for all dimensions of momentary well-being. The latter finding can also be observed for the final indicator of geographical context: accessibility is negatively associated with life satisfaction but has no statistically significant $(p<0.05)$ effect on momentary or day-level well-being. The result that participants who reside in a location that offers greater access to human activity are less satisfied with life indicates that our gravity-based accessibility measure is more comparable to density and urbanization degree in earlier studies (Brereton, Clinch and Ferreira 2008; Berry and Okulicz-Kozaryn 2009; Morrison 2011) than to the accessibility indicators used by Brereton and colleagues (2008, 2011), Morrison (2011) and Arifwidodo (2012).

With regard to social contact, the analysis indicates that "doing it together is better than doing it alone" (Walker 2010,9): undertaking activities without companion is associated with significantly lower scores on all indicators. Differences between types of companions are in many cases fairly limited; only for activation and goal realization are the differences between family/relatives/partner and (online) friends statistically significant, and undertaking activities with acquaintances is associated with higher levels of activation and more positive experiences for the day as a whole. While the comparison is difficult to make, Table 2 also seems to suggest that the effect on well-being of companionship is larger than that of one's 
social network: the correlation between the number of social contacts last week and all wellbeing indicators is positive but the relationships are (very) weak and only statistically significant for half of the indicators.

\title{
Modeling results
}

\author{
General discussion
}

The outcomes of the SEM analysis are summarized in Figure 3, which visualizes results from the measurement model, and Tables 3 and 4 . The former includes the unstandardized coefficients in the structural model and the latter a selection of standardized effects on wellbeing.

[Figure 3 and Tables 3-4 here]

Overall the conceptual model in Figure 1 fits the data reasonably well. There is no consensus regarding the assessment of the goodness-of-fit of a SEM analysis (Kline, 2005). However, the most widely used measure is the root mean square error of approximation (RMSEA), which is 0.044 for our model and below the required $0.05(p<0.001)$. The Comparative Fit Index $(\mathrm{CFI})$ is close to 90 percent. $^{3}$

The model fit is much better with episode well-being specified as a latent construct than when the four indicator variables are incorporated independently and directly into the model. Figure 3 shows that the valence score dominates the latent construct (note that all coefficients 
are scaled relative to the coefficient for objective fulfillment, which has been fixed at 1). Taken together the estimated coefficients suggest that activities that generate contentment and serenity, fulfill goals to a greater extent than anticipated, and improve one's mood are associated with the highest level of episode-level well-being.

Figure 3 also indicates that activity place has been specified as a single latent variable constructed out of four site characteristics. The proportions of single-parent households, elderly residents, and people with tertiary education have been dropped because their inclusion resulted in estimation problems (the first variable) or did not improve the model's goodness-of-fit (the final two). Many combinations of observed variables have been considered and specifications with two latent variables - one for the physical and the other for the social dimensions of the site of activity participation - have also been explored but the specification in Figure 3 provides the best goodness-of-fit statistics and generates coefficients for the observed variables that are plausible in both magnitude and sign.

Two general conclusions can be drawn from Table 3. First, there are positive associations between episode-level, day-level, and overall well-being. Insofar as cross-sectional data allow inferences about causality to be made (see above), the causal structure with effects from life satisfaction to day experience and to episode-level well-being and from day experience to momentary well-being produces considerably better goodness-of-fit indices than a model with effects in the opposite direction (RMSEA=0.044, Chi-square $=1707.236$, $\mathrm{CFI}=0.869$ ). While not offering confirmation, these results are at least consistent with the hypothesis that the dispositional impact from long- to short-term well-being is stronger than the accumulation effect from momentary well-being to life satisfaction. As expected, the effect of life satisfaction on day experience is stronger than that on episode well-being, which 
is consistent with the idea - confirmed by Table 3 - that the latter is shaped to a greater extent by situational factors.

Secondly, of the five activity-episode dimensions only activity place has no statistically significant $(p<0.10)$ effect on episode-level well-being. All else equal, well-being increases if activities last longer, and leisure and social visits outside the home closely followed by sleeping generate the highest level of well-being. Leisure at home scores considerable worse yet better than maintenance at home and shopping, errands and personal affairs outside the home. Thus, not only what is done matters from a well-being perspective but also where in the sense of in-home versus out-of-home, at least for leisure and social activities. None of the coefficients for time of day is statistically significant $(p<0.10)$. This differs from previous DRM studies (Stone et al. 2006) but may reflect that the current model controls for the effects of other variables and especially duration, which varies clearly by time of day.

\section{Well-being effects of geographical context}

All else equal, there is no statistically significant effect $(p<0.10)$ of the site where the activity episode is conducted on momentary well-being. While suggesting that the very modest correlations that were observed in the bivariate analysis (Table 2) reflect the effects of thirdparty variables, this finding does not imply that the geographical context is irrelevant to variations in momentary well-being. There are clear spatial sorting effects in activity participation (Table 3): out-of-home activities and activities undertaken with others - in particular with friends - tend to be undertaken in richer, lower-density areas with less public housing. Activities are also concentrated in such areas if undertaken by employed or higherincome study participants. The same holds for the activities of respondents with less contact 
with their social networks, who do not live in public housing, or who reside in locations offering lower accessibility to spatial opportunities for activity participation. It is unclear whether the activity place construct would have had no effect on momentary well-being, had this spatial sorting not taken place. Additionally, it is also possible that there are other, more appropriate variables from which a latent construct for activity place can be constructed, or that the variables we have used are subject to the modifiable areal unit problem (Openshaw 1983) and would have rendered different results if place had been measured on a more refined geographical scale we were unable to consider in this analysis.

Our analysis also suggests that the effects of accessibility from home on well-being are small. The direct and total effects on momentary well-being are not statistically significant at $p<0.10$, and the same holds for the total effect on day experience. ${ }^{4}$ For overall well-being a significant negative relationship can be detected with life satisfaction being higher as accessibility is lower. This reinforces the conclusion that our accessibility variable is comparable to the indicators for urbanization level and density used by Morrison (2011), Brereton and colleagues $(2008,2011)$ and Berry and Okulicz-Kozaryn (2011) and suggests that their conclusions can be extended to the intra-urban scale, at least in Hong Kong.

Table 4 illustrates two further points regarding the variations in well-being according to accessibility from home. One is that the magnitude of the effect increases once we move from episode well-being to overall life satisfaction. The other is that the effects of accessibility are small compared to variations in well-being along lines of education and in particular income are much larger. For our participants the standardized total effect for income is 3.7 times greater for episode well-being and 7.3 times greater for life satisfaction. Accessibility matters 
to understanding variations in experienced well-being, but other factors are clearly more important.

Well-being effects of social contacts

The model confirms that well-being is directly and indirectly affected by whether an activity is undertaken with others and with whom. In terms of direct effects, undertaking an activity alone produces lower levels of momentary well-being than when others are involved. The coefficient for family/relative(s) and/or partner is larger than for (online) friend(s) and/or acquaintance(s) -0.079 versus 0.053 - but the difference is too small to be statistically significant. What matters most for well-being, then, is whether or not people who are relatively close to the person in question are involved in the activity.

Yet, the model outcomes go beyond the descriptive results in Section 4. There is also a statistically significant indirect effect of companionship on episode-level well-being via activity duration in the model. This indirect effect is $+0.0015\left(0.145^{*} 0.010\right)$ for undertaking an activity together with family/relative(s) and/or partner and $+0.0050(0.496 * 0.010)$ for friends. Thus, the well-being benefits of doing something with friends are more durationdependent than those of undertaking an activity with one's partner, family and/or relative(s). Notwithstanding their small magnitude, the calculated coefficients indicate that, all else equal, spending an hour with friends adds almost 50 percent more value in terms of episode-level well-being than spending an hour without companions. The corresponding value for family/relative(s) and/or one's partner is approximately 15 percent. Figure 4 displays all these effects graphically; extrapolation of the depicted lines indicates that after almost $7 \mathrm{~h}$ the well- 
being benefits of undertaking an activity with friends are identical to those for being with family and/or one's partner.

[Figure 4 here]

The associations of the number of social contacts last week and well-being are small and not statistically significant $(p<0.10)$ at the episode and day levels. This holds for both the direct and the total effects. There is, however, an interesting difference with the effects of companionship. The latter decrease in size if we move from episode-level well-being via day experience to life satisfaction, but for the number of social contact last week the effects become larger along that trajectory. The number of contacts last week has a markedly stronger effect on life satisfaction than on the other two well-being variables. These findings underline the importance of considering both long-term and short-term well-being when analyzing the effects of social contact.

Well-being effects of life circumstances

In line with Clark, Frijters and Shields (2008) we find that a higher income is related to higher levels of well-being, although the effects on day experience and momentary wellbeing result from indirect relations via life satisfaction. The effects of education are only statistically significant $(p<0.10)$ for life satisfaction but have a negative sign across all wellbeing indicators, which suggests the importance of not restricting measurements of socioeconomic status in well-being research to income alone. The effect of housing type is statistically significant for overall well-being at $p<0.01$, indicating that people in public housing are on average less satisfied with life. Employed participants have lower scores on 
day experience and life satisfaction yet also experience higher levels of episode well-being than non-employed participants. These differences seem to reflect participation in paid work and commuting, which makes those in employment appreciate and benefit from the considered non-employment activities but on average also less positive about the day and life as a whole.

For age we find that study participants aged 50 or more experience the highest level of wellbeing and little evidence for a minimum in middle age (Blanchflower and Oswald 2008): those aged 11-29 tend to experience less momentary well-being and only marginally higher life satisfaction and day experience than those who are 30-49 years old. Men tend to experience lower well-being than women irrespective of the indicator used, while the effects of household size are only minor. As with the number of social contacts last week and accessibility from home, the variations in well-being in terms of life circumstances tend to be larger for the life satisfaction than for the episode-level measure.

\section{Conclusions and Discussion}

Utilizing multiple well-being measures and data from a sample of Hong Kong people, this article contributes to the literature on well-being in geography and beyond in various ways. Our advanced modeling approach suggests that space matters but not to the same extent for different dimensions of well-being: the effect of geographical context on overall well-being (life satisfaction) appears to be much stronger than on momentary well-being (Hypothesis A). As far as life satisfaction is concerned, our findings extend earlier work (Brereton, Clinch and Ferreira 2008; Brereton et al. 2011; Berry and Okulicz-Kozaryn 2011; Morrison 2011) by 
suggesting that the inverse relation between overall well-being and level of urbanization can also be observed at the intra-urban scale, at least in Hong Kong and when a gravity-based accessibility measure is employed.

Nonetheless, the fact that the association of momentary well-being with the physical and social dimensions of the place where participants actually undertook activities was not statistically significant is reason for caution. Our study underscores the relevance of the uncertain geographical context problem to studies of the geography of well-being, even though the use of other indicators might have generated different outcomes and the analysis might have been subject to the modifiable areal unit problem. ${ }^{5}$ On balance, however, our analysis is less likely to render a spurious relation between momentary well-being and geographical context than if we had relied on indicators of the physical and social characteristics of the residential neighborhood. We therefore believe that subsequent (quantitative) research by geographers and others should move beyond exclusively relying on geographical indicators based on where people live to considering indicators of where they are at specific moments in time they want to grasp contextual influences on time and place specific well-being (cf. Kwan, 2012).

Obviously, these reflections on UGCoP also complicate the interpretation of the statistically significant effect of accessibility on life satisfaction: Will it be observable if an activity space based accessibility measure is used (Kwan 2012)? And if so, what is the causal mechanism? Does it reflect a long-term accumulation effect whereby spatial behavior and neurological processes interact in complex ways (see also Lederbogen et al. 2011)? Questions like these open up an interdisciplinary research agenda regarding the spatiality of well-being that 
transcends the boundaries between the social sciences, including geography, and the life sciences.

The second contribution of the analysis concerns the positive associations between social contact and well-being (Hypothesis B). Our time-geographical study extends earlier research (Helliwell and Putnam 2004; Lyubomirsky, King and Diener 2005) by showing how the effects of spending time with others are complex and operate across multiple time-scales. Among the study participants we have observed both longer-term positive effects of activity participation with one's social ties and more immediate effects of undertaking nonemployment activities together with relatives, friends or others on experienced well-being in specific places and times. No major difference as regards with whom - family versus friends/acquaintances - could be detected from the direct effects in the SEM. Differences between types of social ties only became apparent when the situational variations in momentary well-being were examined in more detail and the greater duration sensitivity of the well-being effects of being with friends/acquaintances versus being with family members was explored (Figure 3). We did not find any interaction between the character of the place and whether time was spent alone or with others but this might have been different had we been able to consider other place attributes.

The ways in which social contact and well-being are interrelated in our model signals the inadequacy of incorporating simple indicators of ego-centered social networks and social capital in quantitative empirical studies of experienced well-being. Such a strategy is too reductive, and incurs the risk of naïve conclusions and policy recommendations. It should also be appreciated that our findings do not imply that time and place specific well-being will necessarily be higher if people spend more time together with others. This is, among others, 
because for most people a day consists of a sequence of episodes in which different (groups of) persons are met and time is also spent in relative isolation. It may well be that this very variation in whether one interacts with others over the course of a day or week and if so with whom is beneficial from a well-being perspective (Oerlemans, Baker and Veenhoven 2011). This in turn points towards the limitations of considering activity episodes as independent units as we did, and highlights the need to analyze unfolding sequences of such episodes in subsequent research.

The final contribution is that our cross-sectional analysis also raises the possibility - to be verified in longitudinal research - that the dispositional impact from long-term contentment and happiness on momentary well-being is stronger than the opposite effect (Hypothesis C). What is more, there exist a range of interesting differences between the shorter and longerterm aspects and measures of well-being among our study participants. One such difference is that life circumstances are more strongly correlated with life satisfaction, whereas activity participation characteristics are, unsurprisingly, associated more clearly with episode wellbeing. These findings imply that quantitative analysis of subjectively experienced well-being should not be limited to either momentary well-being as a function of time use (Kahneman et al. 2004, 2006) or - as in most spatial-analytical research into subjectively experienced wellbeing to date - to life satisfaction alone. Both need to be analyzed and ideally within a single framework, given that our analysis shows geographical and social context and life circumstances to be differentially related to different facets of well-being.

\section{Endnotes}


1. This approach to subjective well-being is commonly called hedonic but it is slightly broader as cognitive evaluations of how well life is - life satisfaction - are often used in empirical research. Recently there has also been a rapprochement between hedonic and eudaimonic perspectives in psychology (Diener et al. 2010).

2. The Hong Kong Special Administrative Region was established on July 1, 1997 when its sovereignty was transferred from the United Kingdom to the People's Republic of China after about 150 years of British ruling of the territory.

3. The Chi-square statistic is 1682.9 and statistically different from zero $(p<0.001)$. Because this is common with SEM analysis with more than 200 cases, we can disregard this statistic (which is done quite often in the SEM community).

4. There is a statistically significant $(p<0.05)$, positive direct effect of accessibility on day experience, which is to some extent cancelled out by the indirect effect via life satisfaction. The direct effect is difficult to explain and we are tempted to consider it a contingency that is specific to the utilized data.

5. Future research would benefit from employing more refined indicators than we had available of who/what is present - including nature and green space - on a particular site at a specific time, of that site's atmosphere, of the socio-spatial inequalities characterizing that site, and of differences between the social characteristics of that site and the social identity of the persons whose wellbeing is examined. It should also experiment with different zonal classification schemes and with defining explanatory variables at multiple geographical scales.

\section{Acknowledgements}

The reported research was financed by two General Research Fund grants (HKBU244610 and HKBU245008) from Hong Kong Research Grant Council. The article has benefited greatly from the helpful comments by the reviewers and Richard Wright. 


\section{References}

Arifwidodo, S. D. 2012. Exploring the effect of compact development policy to urban quality of life in Bandung. City, Culture and Society 3 (4): 303-311.

Atkinson, S., S. Fuller, and J. Painter. 2012. Wellbeing and Place. Farnham, UK: Ashgate.

Ballas, D. 2013. What makes a 'happy city'? Cities, DOI:

http://dx.doi.org/10.1016/j.cities.2013.04.009.

, and D. Dorling. 2012. The geography of happiness. In Oxford Handbook of Happiness, ed. S.

David, I. Boniwell, and A. Conley Ayers, 465-481. Oxford: Oxford University Press.

and M. Tranmer. 2012. Happy people or happy places?: a multilevel modelling approach to the analysis of well-being. International Regional Science Review 35 (1): 70-102.

Berry, B. J. L., and A. Okulicz-Kozaryn. 2011. An urban-rural happiness gradient. Urban Geography 32 (6): 871-883.

Binkley, S. 2011. Happiness, positive psychology and the program of neoliberal governmentality. Subjectivity 4: 371-394.

Blanchflower, D. G., A. J. Oswald. .2008. Is well-being U-shaped over the life cycle? Social Science and Medicine 66 (8): 1733-1749.

Bollen, K. A. 1989. Structural Equations with Latent Variables. New York: John Wiley \& Sons.

Browne, M. W. 1984. Asymptotically distribution-free methods for analysis of covariance structures. British Journal of Mathematical and Statistical Psychology 37 (1): 62-83.

Brereton, F., P. Clinch, and S. Ferreira. 2008. Happiness, geography and the environment. Ecological Economics, 65 (2): 386-396.

, C. Bullock, P. Clinch, M. Scott. 2011. Rural change and individual well-being: the case of Ireland and rural quality of life. European Urban and Regional Studies 18 (2): 203-227.

Clark, A. E, P. Frijters, M. A. Shields. 2008. Relative income, happiness, and utility: an explanation of the Easterlin paradox and other puzzles. Journal of Economic Literature 46 (1): 95-144. 648-659.

and A. J. Oswald. 1994. Unhappiness and unemployment. The Economic Journal 104 (424):

CSD. 2012. Hong Kong Statistics: Demographic Characteristics. Available at:

http://www.censtatd.gov.hk/hong kong statistics/gender/demographic/index.jsp.

2011a. Hong Kong Annual Digest of Statistics 2011. Hong Kong: Census and Statistics

Department Hong Kong Special Administrative Region, People's Republic of China.

2011b. Hong Kong Statistics: Labour, July-Sept 2011. Available at:

http://www.censtatd.gov.hk/hong kong statistics/statistics by subject/index.jsp?subjectID=2\&charse $\underline{\mathrm{tID}=2 \& \text { displayMode }=\mathrm{T}}$. 
- 2010. Hong Kong Quarterly Report on General Household Survey: October to December 2010. Hong Kong: Census and Statistics Department Hong Kong Special Administrative Region, People's Republic of China.

2007. Demographic Trends in Hong Kong 1981-2006. Hong Kong: Census and Statistics Department Hong Kong Special Administrative Region, People's Republic of China.

Currie, G., and A. Delbosc. 2010. Modelling the social and psychological impacts of transport disadvantage. Transportation 37 (6): 953-966.

Cutrona, C. E., D. W. Russell, P. A. Brown, L. A. Clark, R. M. Hessling, and K. A. Gardner. 2005. Neighborhood context, personality, and stressful life events as predictors of depression among African American women. Journal of Abnormal Psychology 114 (1): 3-15.

Diener, E. 2009. The Science of Well-being: The Collected Works of Ed Diener, Volume 1. Dordrecht: Kluwer.

—, D. Wirtz, W. Tov, C. Kim-Prietro, D. Choi, S. Oishii, and R. Biswas-Dierner. 2010. New well-being measures: short scales to assess flourishing and positive and negative feelings. Social Indicators Research 97 (2): 143-156.

Dolan, P., T. Peasgood, and M. White. 2008. Do we really know what makes us happy? A review of the economic literature on the factors associated with subjective well-being. Journal of Economic Psychology 29 (1): 94-122.

Easterlin, R. A. 1995. Will raising incomes raise the happiness of all? Journal of Economic Behaviour \& Organization 27 (1): 35-47.

Elgar, F. J., C. G. Davis, M. J. Wohl, M.J., S. J. Trites, J. M. Zelenski, and M. S. Martin. (2011), Social capital, health and life satisfaction in 50 countries. Health \& Place 17 (5): 1044-1053.

Ettema, D., T. Gärling, L. E. Olsson, M. Friman. 2010. Out-of-home activities, daily travel, and subjective well-being. Transportation Research Part A: Policy and Practice 44 (9): 723-732.

Fereirra, S., A. Akay, F. Brereton, J. Cuñado, P. Martinsson, and M. Moro. 2013. Life satisfaction and air quality in Europe. Ecological Economics 88: 1-10.

Finney S.J., and C. DiStefano. 2006. Non-normal and categorical data in structure equation modeling. In Structural Equation Modeling: A Second Course, ed. G. R. Hancock, and R. O. Mueller, 268-314. Charlotte, NC: Information Age Publishing.

Fleuret, S., and S. Atkinson. 2007. Wellbeing, health and geography: A critical review and research agenda. New Zealand Geographer 63 (2): 106-118.

Geurs, K., and B. van Wee. 2004. Accessibility evaluation of land-use and transport strategies:

Review and research directions. Journal of Transport Geography 12 (2): 127-140.

Guite, H. F., C. Clark, and G. Ackrill. 2006. The impact of the physical and urban environment on mental well-being. Public Health 120: 1117-1126.

Hägerstrand, T. 1985. Time-geography: focus on the corporeality of man, society, and environment. In The Science and Practice of Complexity, ed. S. Aida, 193-216. Tokyo: The United Nations University. 
Helliwell, J. F. 2006. Well-being, social capital, and public policy: what's new? The Economic Journal, 116 (510): C34-C45.

, and R. D. Putnam. 2004. The social context of well-being. Philosophical Transactions of the Royal Society B: Biological Sciences 359 (1449): 1435-1446.

HKHA. 2011. Housing in Figures 2011 [in Chinese]. Hong Kong: Hong Kong Housing Authority, The Government of the Hong Kong Special Administrative Region, People's Republic of China.

Kahneman, D., and A. B. Krueger. 2006. Developments in the measurement of subjective well-being. Journal of Economic Perspectives 20 (1): 3-24.

Kahneman, D., A. B. Krueger, D. Schkade, N. Schwarz, and A. A. Stone. 2004. A survey method for characterizing day life experience: the day reconstruction method. Science 306: 1776-1780.

2006. Would you be happier if you were richer? A focusing illusion. Science 312: 1908-1910.

Kennedy, D. P., and R. Adolphs. 2011. Stress and the city. Nature 474: 452-453.

Kitamura, R., C. Chen, and R. Narayan. 1998. Traveler destination choice behavior: effects of time of day, activity duration, and home location. Transportation Research Record 1645: 76-81.

Kitamura, R., L. P. Kostyniuk, and M. J. Uyeno. 1981. Basic properties of urban time-space paths: empirical tests. Transportation Research Record 794: 8-19.

Kwan, M. P. 2012. The uncertain geographic context problem. Annals of the Association of American Geographers 102 (5): 958-968.

Layard, R. 2010. Measuring subjective well-being. Science 327: 534-535.

Lederbogen, F., P. Kirsch, L. Haddad L., F. Streit, H. Tost, P. Schuch, S. Wüst, J. C. Pruessner, M. Rietschel,M. Deuschle, and A. Meyer-Lindenberg. 2011.City living and urban upbringing affect neural social stress in humans. Nature 474: 498-501.

Lyubomirsky, S., L. King, and E. Diener. 2005a. The benefits of frequent positive affect: does happiness lead to success? Psychological Bulletin 131 (6): 803-855.

Lyubomirsky, S., K. M. Sheldon, and D. Schkade. 2005b. Pursuing happiness: the architecture of sustainable change. Review of General Psychology 9 (2): 111-131.

MacKerron, G., and S. Mourato. 2009. Life satisfaction and air quality in London. Ecological Economics 68 (5): 1441-1453.

Mitchell, R. 2013. Is physical activity in natural environments better for mental health than physical activity in other environments? Social Science \& Medicine 91: 130-134.

Morrison, P. S. 2011. Local expressions of subjective well-being: The New Zealand experience. Regional Studies 45(8): 1039-1058.

Nordbakke, S., and T. Schwanen. 2013. Wellbeing and mobility: a theoretical framework and literature review focusing on older people. Mobilities, DOI: 10.1080/17450101.2013.784542.

Oerlemans, W. G. M., A. B. Bakker, and R. Veenhoven. 2011. Finding the key to happy aging: A day reconstruction study of happiness. Journal of Gerontology B: Psychological Sciences 66 (6): 665-674. 
Openshaw, S. 1983. The modifiable areal unit problem. Norwick: Geo Books.

Oswald, A. J., and S. Wu. 2010. Objective confirmation of subjective measures of human well-being: Evidence from the U.S.A. Science 327: 576-579.

Pacione, M. 2003. Urban environmental quality and human wellbeing-a social geographical perspective. Landscape and Urban Planning, 65(1): 19-30.

Pred, A. 1983. Structuration and place: On the becoming of sense of place and structure of feeling. Journal for the Theory of Social Behavior 12 (1): 45-68.

Ritchey, L. H., P. N. Ritchey, and B. E. Dietz. 2001. Clarifying the measurement of activity. Activities, Adaptation \& Aging 26 (1): 1-21.

Russell, J. A. 1980. A circumplex model of affect. Journal of Personality and Social Psychology 39 (6): 1161-1187.

(1): $145-172$.

2003. Core affect and the psychological construction of emotion. Psychological Review 110

Ryan, R. M., and E. L. Deci. 2001. On happiness and human potentials: A review of research on hedonic and eudaimonic well-being. Annual Review of Psychology 52: 141-166.

Ryff, C. D. 1989. Happiness is everything, or is it? Explorations of the meaning of psychological well-being. Journal of Personality and Social Psychology 52 (6): 1069-1081.

Schwanen, T. 2004. The determinants of shopping duration on workdays in the Netherlands. Journal of Transport Geography 12 (1): 35-48.

Smith, D. M. 1973. The geography of social well-being in the United States: An introduction to territorial social indicators. New York: McGraw-Hill.

Stanca, L. 2010. The geography of economics and happiness: spatial patterns in the effects of economic conditions on well-being. Social Indicators Research 99 (1): 115-133.

Stiglitz, J. E., A. Sen, and J.-P. Fitoussi. 2009. Report by the commission on the measurement of economic performance and social progress. Available at: www.stiglitz-sen-fitoussi.fr.

Stone, A. A., J. E. Schwartz, J.E., D. Schkade, N. Schwarz, A. Krueger, and D. Kahneman. 2006), A population approach to the study of emotion: diurnam rhythms of a working day obtained with the day reconstruction method. Emotion 6 (1): 139-149.

Timmermans, H., T. Arentze, and C.-H. Joh. 2002. Analysing space-time behaviour: New approaches to old problems. Progress in Human Geography 26 (2): 175-190.

Tsai, J.L., B. Knutson, and H.H. Fung. 2006. Cultural variation in affect valuation. Journal of Personality and Social Psychology 90 (2): 288-307.

Van den Bergh, A., J. Maas, R. Verheij, and P. P. Groenewegen. 2010. Green space as a buffer between stressful life and health. Social Science \& Medicine 70 (8): 1203-1210.

Walker, C. J. 2010. Experiencing flow: is doing it together better than doing it alone? The Journal of Positive Psychology 5 (1): 3-11. 
Waterman, A. S. 1993. Two conceptions of happiness: contrasts of personal expressiveness (eudaimonia) and hedonic enjoyment. Journal of Personality and Social Psychology 64 (4): 679-691.

White, M. P., and P. Dolan. 2009. Accounting for the richness of daily activities. Psychological Science 20 (8): 1000-1008.

White, M. P., I. Alcock, B. W. Wheeler, and M. H. Depledge. 2013. Would you be happier living in a greener urban area? A fixed-effects analysis of panel data. Psychological Science, DOI: $10.117 / 0956797612464659$.

Wilkinson, R. and K. Pickett. 2009. The spirit level: why equality is better for everyone. London: Allen Lane. 


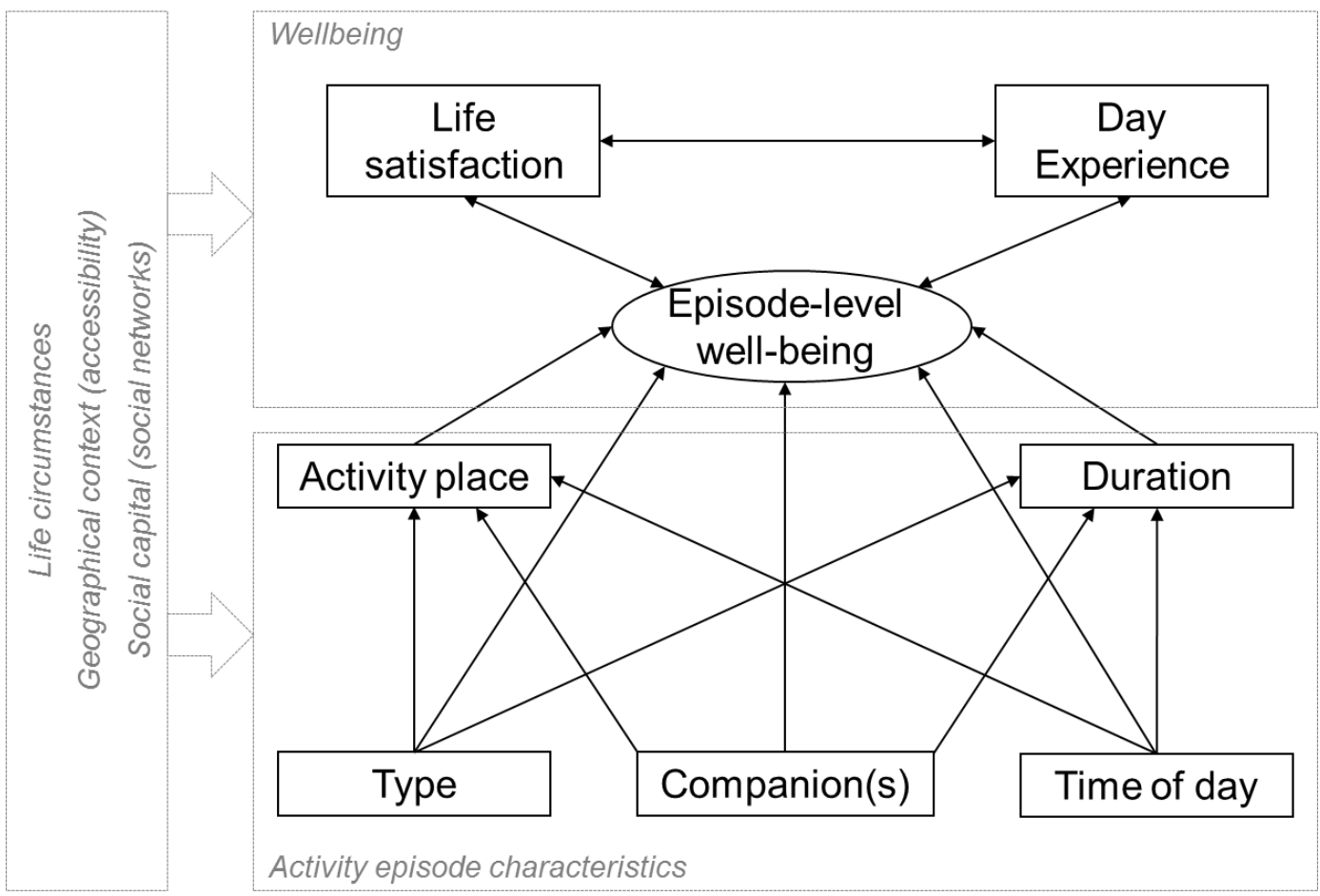

Figure 1. Conceptual relationships. 


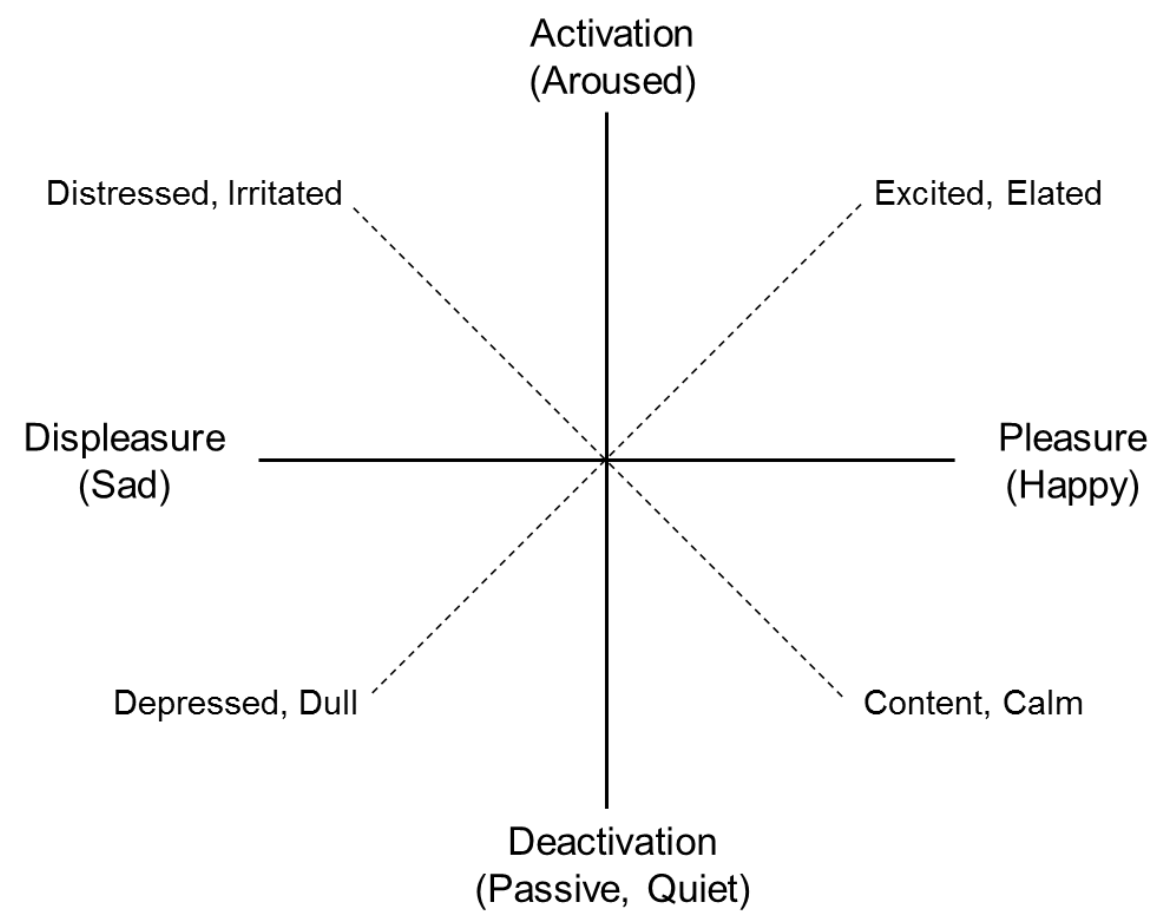

Figure 2. Core affects (freely after Russell, 1980). 


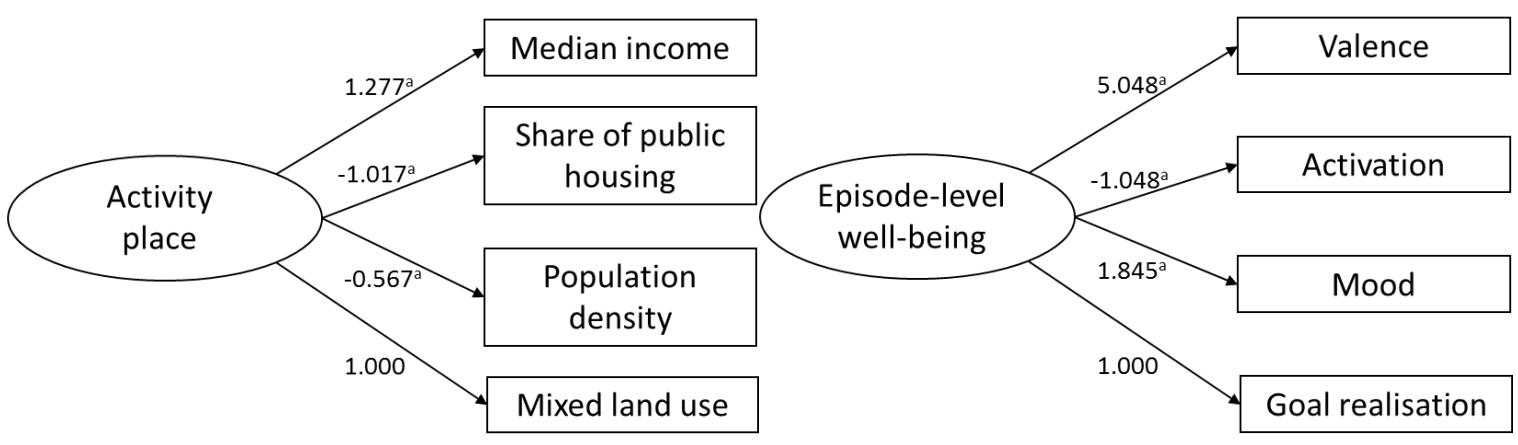

Figure 3. Measurement models for activity place and episode-level well-being. 


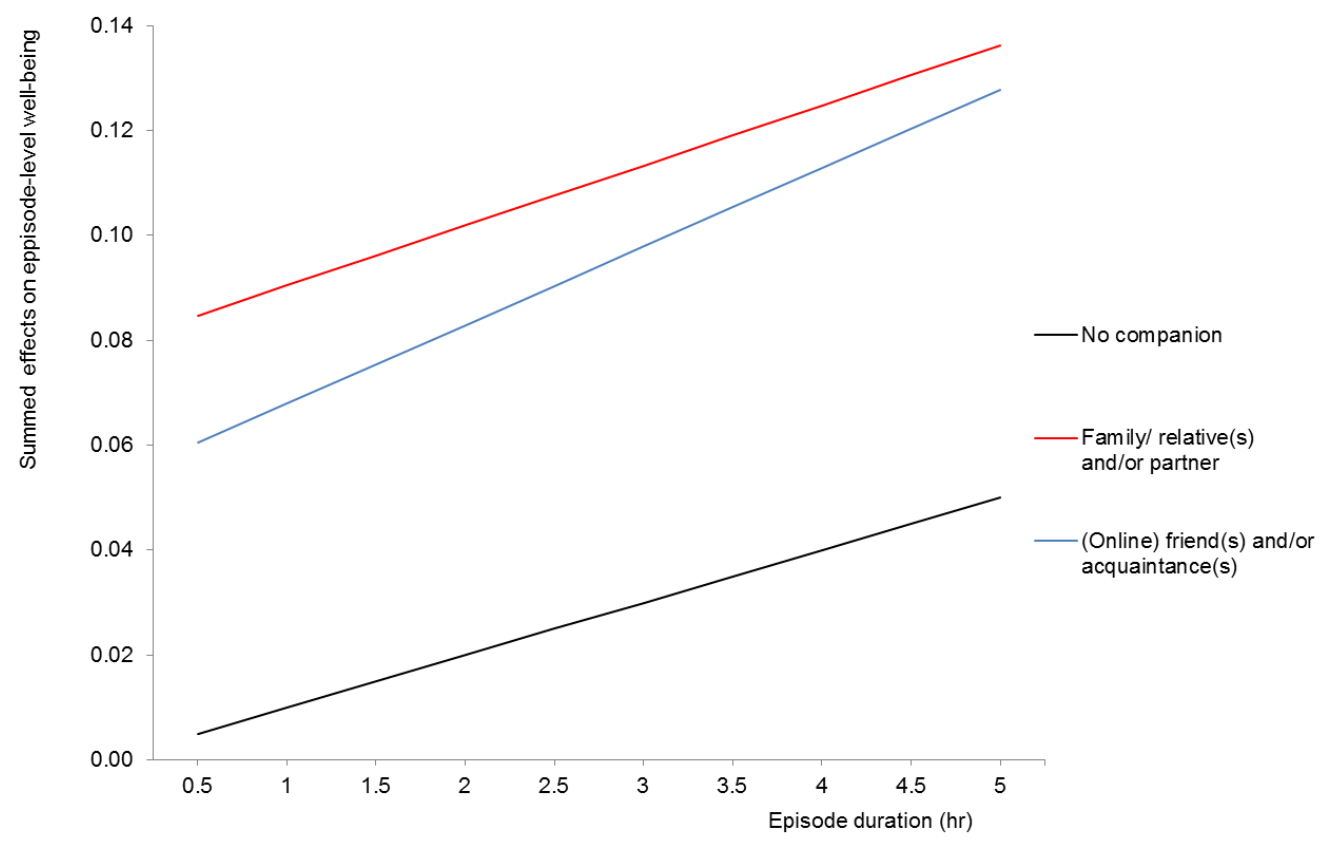

Figure 4. Summed direct and indirect effects of companionship and duration on episode-level wellbeing. 
Table 1. Sample characteristics.

\begin{tabular}{|c|c|c|c|}
\hline & & Sample $(n=770)$ & $\begin{array}{l}\text { Hong Kong SAR } \\
\text { Population }^{1}\end{array}$ \\
\hline Age & $\begin{array}{l}11-29 \text { years } \\
30-49 \text { years } \\
\geq 50 \text { years }\end{array}$ & $\begin{array}{l}48.4 \% \\
36.8 \% \\
15.8 \%\end{array}$ & $\begin{array}{l}25.3 \% \\
33.6 \% \\
34.0 \%\end{array}$ \\
\hline Gender & $\begin{array}{l}\text { Male } \\
\text { Female }\end{array}$ & $\begin{array}{l}41.6 \% \\
58.4 \%\end{array}$ & $\begin{array}{l}46.8 \% \\
53.2 \%\end{array}$ \\
\hline Marital status & $\begin{array}{l}\text { Married } \\
\text { Other }\end{array}$ & $\begin{array}{l}35.4 \% \\
64.6 \%\end{array}$ & $\begin{array}{l}57.8 \% \\
42.2 \%\end{array}$ \\
\hline Citizenship status & $\begin{array}{l}\text { HK Permanent Resident } \\
\text { Other }\end{array}$ & $\begin{array}{c}98.3 \% \\
1.7 \%\end{array}$ & $\begin{array}{c}94.0 \% \\
6.0 \%\end{array}$ \\
\hline $\begin{array}{l}\text { Employment } \\
\text { status }\end{array}$ & $\begin{array}{l}\text { Employed } \\
\text { Others }\end{array}$ & $\begin{array}{l}59.3 \% \\
40.7 \%\end{array}$ & $\begin{array}{l}60.7 \% \\
39.3 \%\end{array}$ \\
\hline Education level & $\begin{array}{l}\text { Post-secondary and less } \\
\text { Undergraduate and higher }\end{array}$ & $\begin{array}{l}48.6 \% \\
51.4 \%\end{array}$ & $\begin{array}{l}68.1 \%^{2} \\
31.9 \%^{2}\end{array}$ \\
\hline $\begin{array}{l}\text { Monthly } \\
\text { household gross } \\
\text { income }\end{array}$ & $\begin{array}{l}\text { HK\$ }<20,000 \\
\text { HK\$ 20,000-39,999 } \\
\text { HK\$ } \geq 40,000\end{array}$ & $\begin{array}{l}37.5 \% \\
36.9 \% \\
25.6 \%\end{array}$ & $\begin{array}{l}52.8 \% \\
28.2 \% \\
19.0 \%\end{array}$ \\
\hline Housing type & $\begin{array}{l}\text { Public housing \& home } \\
\text { ownership scheme } \\
\text { Private housing, village house \& } \\
\text { government quarters }\end{array}$ & $\begin{array}{l}49.8 \% \\
50.2 \%\end{array}$ & $\begin{array}{l}47.7 \% \\
51.8 \%\end{array}$ \\
\hline $\begin{array}{l}\text { Household car } \\
\text { ownership }\end{array}$ & $\begin{array}{l}\text { None } \\
\geq 1 \text { private } \operatorname{car}(\mathrm{s})\end{array}$ & $\begin{array}{l}81.1 \% \\
18.9 \%\end{array}$ & $\begin{array}{l}82.2 \% \\
17.8 \%\end{array}$ \\
\hline
\end{tabular}

${ }^{1}$ Drawn from CSD $(2007,2010,2011 \mathrm{a}, 2011 \mathrm{~b} 2012)$ and HKHA (2011)

${ }^{2}$ Based on people aged $\geq 15$ 
Table 2: Descriptive analysis of wellbeing, by activity type and indicators of social interactions and geographical context ( $n=4,312$ episodes).

\begin{tabular}{|c|c|c|c|c|c|c|c|c|c|c|c|c|c|}
\hline & \multirow{2}{*}{$\begin{array}{c}n \\
\text { cases }\end{array}$} & \multicolumn{2}{|c|}{$\begin{array}{c}\text { Valence } \\
{[1,7]}\end{array}$} & \multicolumn{4}{|c|}{ Episode } & \multicolumn{2}{|c|}{$\begin{array}{c}\text { Goal realisation } \\
{[0,2]}\end{array}$} & \multicolumn{2}{|c|}{$\begin{array}{c}\text { Day } \\
\text { Day experience } \\
{[1,5]}\end{array}$} & \multicolumn{2}{|c|}{$\begin{array}{c}\text { Global } \\
\text { Life satisfaction } \\
{[1,5]}\end{array}$} \\
\hline & & Mean & Corr. $^{1}$ & Mean & Corr. $^{1}$ & Mean & Corr. $^{1}$ & Mean & Corr. $^{1}$ & Mean & Corr. $^{1}$ & Mean & Corr. ${ }^{1}$ \\
\hline \multicolumn{14}{|l|}{ Activity type } \\
\hline Sleeping at home & 1,447 & $5.59^{\mathrm{a}}$ & & $1.92^{\mathrm{a}}$ & & $1.69^{\mathrm{a}}$ & & $1.05^{\mathrm{a}}$ & & $3.40^{\mathrm{a}}$ & & 3.51 & \\
\hline Maintenance at home & 1,247 & 5.37 & & 2.58 & & 1.68 & & 1.06 & & 3.43 & & 3.55 & \\
\hline Shopping, errands \& personal affairs outside home & 687 & 5.42 & & 3.27 & & 1.73 & & 1.10 & & 3.47 & & 3.54 & \\
\hline Leisure at home & 545 & 5.52 & & 2.79 & & 1.71 & & 1.07 & & 3.38 & & 3.52 & \\
\hline Leisure and social visits outside home & 359 & 5.88 & & 3.50 & & 1.87 & & 1.19 & & 3.57 & & 3.58 & \\
\hline \multicolumn{14}{|l|}{ Mixed land use at site of activity } \\
\hline Site with multiple functions & 2,076 & 5.54 & & $2.63^{\mathrm{a}}$ & & 1.71 & & 1.08 & & $3.45^{\mathrm{a}}$ & & $3.59^{\mathrm{a}}$ & \\
\hline Site with mainly tourist functions & 119 & 5.50 & & 2.63 & & 1.67 & & 1.06 & & 3.17 & & 3.66 & \\
\hline Site with mainly residences & 2,117 & 5.48 & & 2.51 & & 1.72 & & 1.07 & & 3.43 & & 3.47 & \\
\hline Population density at site of activity & 4312 & & 0.001 & & 0.011 & & 0.020 & & 0.000 & & 0.011 & & -0.010 \\
\hline Median income at site of activity & 4312 & & 0.021 & & $0.032^{\mathrm{b}}$ & & 0.005 & & -0.005 & & 0.007 & & $0.078^{\mathrm{b}}$ \\
\hline Share of single-parent households at site of activity & 4312 & & $-0.034^{\mathrm{b}}$ & & -0.024 & & -0.009 & & -0.014 & & $-0.044^{\mathrm{b}}$ & & $-0.093^{\mathrm{b}}$ \\
\hline Share of public housing at site of activity & 4312 & & $-0.036^{\mathrm{b}}$ & & -0.023 & & 0.004 & & -0.019 & & -0.027 & & $-0.082^{b}$ \\
\hline Share of elderly residents (65+) at site of activity & 4312 & & -0.013 & & 0.010 & & -0.012 & & 0.009 & & -0.015 & & $-0.035^{b}$ \\
\hline $\begin{array}{l}\text { Percentage of residents with tertiary education at } \\
\text { site of activity }\end{array}$ & 4312 & & 0.025 & & $0.030^{\mathrm{b}}$ & & 0.003 & & 0.003 & & 0.022 & & $0.092^{\mathrm{b}}$ \\
\hline Accessibility from home location & 4,312 & & -0.021 & & 0.002 & & 0.000 & & 0.021 & & 0.022 & & $-0.052^{b}$ \\
\hline \multicolumn{14}{|l|}{ Companionship } \\
\hline Family/relative(s)s and/or partner & 2,455 & $5.58^{\mathrm{a}}$ & & $2.40^{\mathrm{a}}$ & & $1.74^{\mathrm{a}}$ & & $1.07^{\mathrm{a}}$ & & $3.42^{\mathrm{a}}$ & & $3.57^{\mathrm{a}}$ & \\
\hline Friend(s) and/or online friend(s) & 369 & 5.65 & & 3.26 & & 1.80 & & 1.19 & & 3.51 & & 3.54 & \\
\hline Acquaintance(s) & 142 & 5.50 & & 3.78 & & 1.70 & & 1.13 & & 3.61 & & 3.53 & \\
\hline None & 1,342 & 5.35 & & 2.45 & & 1.65 & & 1.05 & & 3.39 & & 3.47 & \\
\hline Number of social contacts last week & 4,312 & & 0.003 & & $0.054^{\mathrm{b}}$ & & $0.036^{\mathrm{b}}$ & & 0.007 & & $0.037^{\mathrm{b}}$ & & 0.027 \\
\hline
\end{tabular}

${ }^{1}$ Spearman's rank correlation

a differences between categories statistically significant with $p<0.05$ (ANOVA); ${ }^{\text {b }}$ Spearman's rank correlation statistically significantly different from zero with $p<0.05$ 
Table 3: Explaining variations in activity attributes and well-being (unstandardized coefficients).

\begin{tabular}{|c|c|c|c|c|c|c|c|}
\hline & \multirow{2}{*}{$\begin{array}{l}\text { Activity duration } \\
\text { Direct effect }(b)^{\dagger}\end{array}$} & \multirow{2}{*}{$\begin{array}{c}\text { Activity place } \\
\text { Direct effect }(b)^{\dagger}\end{array}$} & \multirow{2}{*}{$\begin{array}{l}\text { Life satisfaction } \\
\text { Direct effect }(b)^{\dagger}\end{array}$} & \multicolumn{2}{|c|}{ Day experience } & \multicolumn{2}{|c|}{ Episode well-being } \\
\hline & & & & Direct effect $(b)$ & Total effect $(b)$ & Direct effect $(b)$ & Total effect $(b)$ \\
\hline Life satisfaction & & & & $0.206^{\mathrm{a}}$ & & $0.122^{\mathrm{a}}$ & $0.136^{\mathrm{a}}$ \\
\hline Day experience & & & & & & $0.070^{\mathrm{a}}$ & $0.070^{\mathrm{a}}$ \\
\hline Duration & & & & & & $0.010^{\mathrm{b}}$ & $0.010^{\mathrm{b}}$ \\
\hline Activity place & & & & & & -0.004 & -0.004 \\
\hline \multicolumn{8}{|l|}{ Activity type (sleeping $=0$ ) } \\
\hline Maintenance at home & $-2.215^{\mathrm{a}}$ & -0.011 & & & & $-0.140^{\mathrm{a}}$ & $-0.162^{\mathrm{a}}$ \\
\hline Shopping, errands \& personal affairs outside home & $-2.622^{\mathrm{a}}$ & $0.115^{\mathrm{a}}$ & & & & $-0.149^{a}$ & $-0.175^{\mathrm{a}}$ \\
\hline Leisure at home & $-1.320^{\mathrm{a}}$ & 0.022 & & & & $-0.080^{b}$ & $-0.094^{\mathrm{a}}$ \\
\hline Leisure and social visits outside the home & $2.275^{\mathrm{a}}$ & $0.142^{\mathrm{a}}$ & & & & 0.017 & -0.007 \\
\hline \multicolumn{8}{|l|}{ Companionship $($ none $=0)$} \\
\hline Family/relative(s)s and/or partner & $0.145^{\mathrm{b}}$ & $0.028^{c}$ & & & & $0.079^{\mathrm{a}}$ & $0.080^{\mathrm{a}}$ \\
\hline Friend(s), online friend(s) and/or acquaintance(s) & $0.496^{\mathrm{a}}$ & $0.153^{\mathrm{a}}$ & & & & $0.053^{\mathrm{c}}$ & $0.057^{\mathrm{c}}$ \\
\hline \multicolumn{8}{|l|}{ Time of day $(10: 00 \mathrm{PM}-6: 00 \mathrm{AM}=0)$} \\
\hline $6: 00-11: 00 \mathrm{AM}$ & $0.947^{\mathrm{a}}$ & 0.010 & & & & 0.032 & 0.041 \\
\hline 11:00AM-3:00PM & 0.070 & 0.016 & & & & 0.037 & 0.038 \\
\hline 3:00-6:00PM & $0.902^{\mathrm{a}}$ & 0.021 & & & & -0.005 & 0.004 \\
\hline 6:00-10:00PM & $0.269^{b}$ & 0.013 & & & & 0.026 & 0.029 \\
\hline Accessibility from home & 0.063 & $-0.052^{\mathrm{a}}$ & $-0.151^{b}$ & $0.110^{\mathrm{b}}$ & 0.079 & -0.019 & -0.020 \\
\hline Number of social contacts last week & & $-0.001^{b}$ & $0.002^{\mathrm{b}}$ & 0.000 & 0.001 & -0.000 & 0.000 \\
\hline \multicolumn{8}{|l|}{ Age $(\geq 50$ years $=0)$} \\
\hline $11-29$ years & 0.143 & -0.027 & $-0.247^{a}$ & -0.083 & $-0.134^{b}$ & $-0.062^{b}$ & $-0.094^{\mathrm{a}}$ \\
\hline $30-49$ years & 0.120 & -0.013 & $-0.260^{\mathrm{a}}$ & $-0.112^{b}$ & $-0.166^{a}$ & -0.005 & -0.042 \\
\hline \multicolumn{8}{|l|}{ Gender $($ female $=0)$} \\
\hline Male & $0.094^{\mathrm{c}}$ & -0.022 & $-0.128^{a}$ & -0.043 & $-0.070^{c}$ & $-0.049^{a}$ & $-0.066^{\mathrm{a}}$ \\
\hline Household size & 0.004 & 0.002 & -0.005 & $-0.056^{\mathrm{a}}$ & $-0.057^{\mathrm{a}}$ & $0.015^{\mathrm{b}}$ & 0.008 \\
\hline Education level & $-0.252^{\mathrm{a}}$ & -0.021 & $-0.094^{\mathrm{a}}$ & -0.011 & -0.030 & -0.002 & -0.012 \\
\hline \multicolumn{8}{|l|}{ Employment status $($ non-employed $=0$ ) } \\
\hline Employed & -0.039 & $0.015^{\mathrm{b}}$ & $-0.241^{\mathrm{a}}$ & $-0.154^{\mathrm{a}}$ & $-0.203^{\mathrm{a}}$ & $0.143^{\mathrm{a}}$ & $0.099^{\mathrm{a}}$ \\
\hline Monthly household income & -0.014 & $0.033^{\mathrm{a}}$ & $0.168^{\mathrm{a}}$ & 0.001 & $0.036^{\mathrm{a}}$ & -0.005 & $0.011^{\mathrm{b}}$ \\
\hline \multicolumn{8}{|l|}{ Housing type (other $=0)$} \\
\hline Public housing & -0.026 & $-0.253^{a}$ & $-0.156^{a}$ & $0.084^{\mathrm{b}}$ & 0.052 & -0.003 & -0.007 \\
\hline
\end{tabular}

total effect is identical to total effect

a significantly different from zero at $p<0.01$

${ }^{\mathrm{b}}$ significantly different from zero at $p<0.05$

${ }^{\mathrm{c}}$ significantly different from zero at $p<0.10$ 
Table 4: Standardised effects of selected variables on well-being. ${ }^{1}$

\begin{tabular}{lccccc}
\hline & $\begin{array}{c}\text { Life } \\
\text { satisfaction } \\
\text { Direct } \\
\text { effect }(\beta)\end{array}$ & $\begin{array}{c}\text { Direct } \\
\text { effect } \\
(\beta)\end{array}$ & $\begin{array}{c}\text { Total } \\
\text { effect } \\
(\beta)\end{array}$ & $\begin{array}{c}\text { Direct } \\
\text { effect } \\
(\beta)\end{array}$ & $\begin{array}{c}\text { Total } \\
\text { effect } \\
(\beta)\end{array}$ \\
\hline $\begin{array}{l}\text { Education level } \\
\text { Monthly household income }\end{array}$ & -0.091 & -0.022 & -0.031 & -0.004 & -0.029 \\
$\begin{array}{l}\text { Number of social contacts last } \\
\text { week }\end{array}$ & 0.349 & 0.060 & 0.078 & -0.024 & 0.055 \\
Accessibility from home & 0.051 & 0.019 & 0.026 & -0.009 & 0.006 \\
\hline
\end{tabular}

${ }^{1}$ Effect sizes have been standardised on the basis of standard deviations as follows: $\beta=b *\left(\mathrm{SD}_{x} / \mathrm{SD}_{y}\right)$ 